\title{
Detection of Carbapenemase-producing Klebsiella pneumoniae isolated from Environmental Sources in a Tertiary Health Institution in Nigeria.
}

lloduba Nnaemeka Aghanya ( $\sim$ aghanyailoduba@gmail.com )

Nnamdi Azikiwe University https://orcid.org/0000-0003-4481-4834

Comfort Nne Akujobi

Nnamdi Azikiwe University, Faculty of Medicine

Simon Nkpeh Ushie

Nnamdi Azikiwe University

Chika Florence Ubajaka

Nnamdi Azikiwe University

ljeoma Maryrose Ajuba

Nnamdi Azikiwe University Teaching Hospital

Chibuike Jesse Ezeama

Nnamdi Azikiwe University

Nkechi Perpetua Maduekwe

Nnamdi Azikiwe University Teaching Hospital

Ngozichukwu Gertrude Uzoewulu

Nnamdi Azikiwe University

Chisom Godswill Chigbo

Nnamdi Azikiwe University

Research note

Keywords: Multidrug-resistant, Klebsiella pneumoniae, Carbapenemase, Oxacillinase, Fomites

Posted Date: September 11th, 2020

DOI: https://doi.org/10.21203/rs.3.rs-42624/v2

License: (c) (i) This work is licensed under a Creative Commons Attribution 4.0 International License.

Read Full License 


\section{Abstract}

Objective The acquisition of carbapenemase-producing organisms in healthcare settings is a major threat and has serious implications for public health. Previous reports regarding carbapenemase-producing Enterobacteriaceae from fomites are limited. This study aimed at analysing the antimicrobial resistance patterns, and prevalence of carbapenemase-producing Klebsiella pneumoniae in the ward environments of a tertiary health institution in Nigeria.

Results A total of 142 bacteria were isolated from 534 fomites in the hospital wards, and of the 142 isolates, $15(10.6 \%)$ were confirmed to be Klebsiella pneumoniae. The prevalence of Klebsiella pneumoniae in all the 534 samples was 15/534(2.8\%), while the prevalence of carbapenemase-producing Klebsiella pneumoniae was 8/534(1.5\%). Multi-drug resistance was detected in 15/15(100\%) of the Klebsiella pneumoniae isolated. Although no Klebsiella pneumoniae Carbapenemase ( bla KPC ) gene was expressed in any of these isolates, $8 / 15(53.3 \%)$ of these isolates were confirmed positive for carbapenemase production using the Modified Hodge Test. The commonest sites that harboured carbapenem-resistant Klebsiella pneumoniae were the beds 6/15(40\%). Maximum resistance $(100 \%)$ was observed against ampicillin, trimethoprim-sulfamethoxazole, cefuroxime, and tetracycline. In conclusion, the prevalence of carbapenemase-producing Klebsiella pneumoniae fomite colonization in the NAUTH ward environment is low, thus buttressing the need to reinforce strict infection control policies the hospital.

\section{Introduction}

Klebsiella pneumoniae are Gram-negative, non-motile, encapsulated bacilli belonging to the family of bacteria called the Enterobacteriaceae.[1] They are considered the second most common cause of healthcare-associated sepsis, remaining for long periods in hospital environments and equipment, and may be spread to patients by contact with these environmental surfaces.[2][3] They develop resistance by various mechanisms, but by far, the most troublesome of these are the carbapenemases which make the organisms resistant to almost all forms of antibiotics, especially carbapenems which have been considered as agents of last resort in the treatment of infections caused by MDR Gram-negative bacilli.[4] [5]

The burden of anti-microbial resistance (AMR) in developing countries has increased remarkably in recent years.[6][7] In a 2017 review of AMR in Africa, only about $60 \%$ of the countries had available data on AMR. There was a strikingly high median resistance (MR) rate for the Enterobacteriaceae to ampicillin (MR= 88.1\%).[6] Resistance was however uncommon for the carbapenem group of antibiotics. In particular, Klebsiella spp. which has intrinsic resistance to ampicillin, was resistant to $34.2 \%$ and $46.7 \%$ of ceftriaxone or cefotaxime respectively, suggesting high-level extended-spectrum beta-lactamase (ESBL) production. However, the median resistance rate for $K$. pneumoniae against Imipenem, a carbapenem was 3.0\%.[6] In another survey involving Africa and Asia, resistance to ampicillin and ceftriaxone were reported as $67.2 \%$ and $25.9 \%$ respectively.[7] 
The most frequently detected carbapenemases include class A- Klebsiella pneumoniae Carbapenemase (KPC) types), class B- metallo- $\beta$-lactamases (MBLs) viz Verona integron-encoded metallo- $\beta$-lactamase

(VIM) and NewDelhi metallo- $\beta$-lactamase (NDM) types, and class D- oxacillinases (OXA-48-like enzymes). [8] Furthermore, the KPCs have been documented as major causes of nosocomial outbreaks.[9][10][11]

Several studies done previously on carbapenemase detection focused more on isolates from clinical specimens of patients, but limited information is found in the literature on the prevalence of carbapenemase-producing Klebsiella pneumoniae in the hospital environment. One environmental study worthy of note was that in which the prevalence of carbapenemase-producing Klebsiella pneumoniae was determined in environmental sites of Intensive Care Units (ICUs) in Cairo, Egypt.[12] This study, therefore, aimed at determining the occurrence of carbapenemase-producing Klebsiella pneumoniae in the ward environments of a tertiary health institution in Nigeria.

\section{Methods}

\section{Study Population}

One hundred and forty-two human bacterial pathogens were isolated from 534 environmental specimens obtained in the wards of NAUTH, Nnewi, a major referral centre serving individuals from most parts of South-East, Nigeria. The bacteria were collected between January 2018 and June 2018, and the specimens included swabs collected from; patients beds, bedside tables, bedside cupboards, trolleys, sphygmomanometers, water taps, antiseptics, disinfectants, hand wash solutions, hand sanitizers, forceps, wheel chairs, kidney dishes, door handles, drip stands, drug mortars, methylated spirits, suction tubes, nurses desks, doctors desks and pulse oximeters.

\section{Bacterial Isolation}

Duplicate swabs were collected by rolling moistened sterile swab sticks over the sites mentioned above for about 5 seconds. These swabs were sent to the laboratory immediately after collection and cultured on chocolate and Mac Conkey agar (Oxoid, UK) and incubated at $35-37^{\circ} \mathrm{C}$ for 24 hours.[10][12] The isolates were Gram-stained, and the Gram-negative rods were subjected to confirmatory identification of Klebsiella pneumoniae using the Microbact ${ }^{\mathrm{TM}}$ Gram-negative bacteria identification kit (Oxoid, UK).[10]

\section{Antimicrobial Susceptibility testing}

The Modified Kirby-Bauer antimicrobial susceptibility testing technique was performed on all isolates confirmed as Klebsiella pneumoniae.[13][14] A lawn of each bacterial inoculum equivalent to $1.5 \times 10^{8}$ $\mathrm{CFU} / \mathrm{ml}$, was made on the surface of a Mueller-Hinton agar (Oxoid, UK) plate using a sterile swab stick and left to dry for 3-5 minutes. Antibiotics were then placed on the lawn, and the plates incubated aerobically at $35-37^{\circ} \mathrm{C}$ for $16-18$ hours. The zones of growth inhibition around each antibiotic disc was measured and reported based on the guidelines of the CLSI.[14] 


\section{Screening for suspected carbapenemase production}

Screening involved placing 10 $\mu$ g carbapenem (ertapenem and meropenem) discs (Oxoid, UK) on the surface of Mueller Hinton agar (Oxoid, UK) plates inoculated with each isolate. Following incubation of the plates for $16-18$ hours at $35-37^{\circ} \mathrm{C}$, zones of growth inhibition around each antibiotic were read off. Klebsiella pneumoniae isolates that showed a zone of inhibition $\leq 22 \mathrm{~mm}$ in diameter for meropenem or $\leq 21 \mathrm{~mm}$ for ertapenem were considered as suspected carbapenemase producers and were subjected to phenotypic confirmation by the Modified Hodges Test (MHT)[11][14].

\section{Phenotypic confirmation of carbapenemase production (Modified Hodges Test)}

In this method, a suspension of E. coli ATCC 25922 equivalent to 0.5 McFarland turbidity standard was prepared. The $E$. coli suspension was then diluted $1: 10$ by adding $0.5 \mathrm{ml}$ of the $E$. coli suspension to 4.5 $\mathrm{ml}$ of saline. A lawn of the 1:10 dilution of E. coli ATCC 25922 was evenly streaked onto Mueller Hinton agar plates using sterile cotton swabs and then allowed to dry for 3-5 minutes. One disc of Meropenem $(10 \mu \mathrm{g})$, was placed on the centre surface of the MHA plate. In a straight line, using a sterilized wire loop, the test organisms were streaked from the edge of each Meropenem disc to the edge of the plate. The plates were incubated at $37^{\circ} \mathrm{C}$ for 24 hours. After incubation, they were examined for a clover leaf type indentation at the intersection of the test organism and E. coli ATCC 25922 within the zone of inhibition of the meropenem disc as described by the CLSI.[14] K. pneumoniae ATCC 1705 and K. pneumoniae ATCC 1706 were used as positive and negative controls.[14]

\section{Molecular Detection of bla $\mathrm{KPC}_{\mathrm{K}}$}

Bacteria DNA from the Klebsiella pneumoniae isolates was extracted using a previously described boiling method for DNA extraction with slight modifications.[15][16] The extracted DNA was quantified and tested for purity using the NanoDrop ${ }^{\circledR}$ ND-1000 spectrophotometer (Additional file 1: Table S1). The bla $_{\text {KPC }}$ gene was detected using a conventional PCR reaction that was based on the protocols and primer sequences previously published by Shanmugam et al., [17] with slight modifications. (Additional file 2: Table S2).

The PCR conditions for bla $\mathrm{KPC}_{\mathrm{K}}$ detection were as follows: initial denaturation at $94^{\circ} \mathrm{C}$ for 3 minutes, followed by 30 cycles of denaturation at $94^{\circ} \mathrm{C}$ for 1 minute, annealing at $60^{\circ} \mathrm{C}$ for 1 minute, extension at $72^{\circ} \mathrm{C}$ for 1 minute, then final extension at $72^{\circ} \mathrm{C}$ for 5 minutes. The products were then resolved at $130 \mathrm{~V}$ for 25 minutes on $1.5 \%$ agarose gel stained with $0.5 \mu \mathrm{g} / \mathrm{ml}$ ethidium bromide solution (Nippon Genetics, Europe $\mathrm{GmbH}$ ) in an electrophoresis tank containing $1 \mathrm{mMol}$ Tris-Borate EDTA (TBE) buffer. The gels were observed under UV gel Transilluminator (UV DOC, England) at 280nm and the band pattern observed.

\section{Data Analysis}


Statistical analysis was done using STATA version 13 (Stata Corp LP, Texas, USA). Frequency distribution tables were used to determine rates.

\section{Results}

The prevalence of bacterial contamination in the total sample population was $142 / 534(26.6 \%)$. Out of these, $15(10.6 \%)$ were identified as Klebsiella pneumoniae, thus, the prevalence of the Klebsiella pneumoniae in the entire sample population was 15/534(2.8\%). (Additional file 3: Table S3).

The Male Surgical Ward had the highest proportion of Klebsiella pneumoniae isolates 5(33.3\%), followed by the Male and Female Medical wards which had 3(20\%) each. (Additional file 4: Table S4).

The highest resistance pattern (100\% resistant) was seen against Ampicillin, Trimethoprimsulphamethoxazole, Cefuroxime and Tetracycline, while the least amount of resistance was seen in the carbapenem class of antibiotics including Imipenem (26.7\%), Meropenem (40.0\%) and Ertapenem (46.7\%). (Table 1) (Additional file 5: Table S5).

Table 1: Antibiogram of the Klebsiella pneumoniae Isolates 


\begin{tabular}{|c|c|c|c|c|}
\hline \multirow[t]{2}{*}{ Antibiotic Class } & \multirow[t]{2}{*}{ Antibiotic } & \multirow{2}{*}{$\begin{array}{l}\text { Disk } \\
\text { content }\end{array}$} & \multirow{2}{*}{$\begin{array}{l}\text { Susceptible } \\
\mathrm{n}(\%)\end{array}$} & \multirow{2}{*}{$\begin{array}{l}\text { Resistant } \\
\mathrm{n}(\%)\end{array}$} \\
\hline & & & & \\
\hline Penicillins & Ampicillin & $10 \mu g$ & $0(0.0)$ & $15(100.0)$ \\
\hline B-lactam/B-lactamase & Amoxicillin- & $20 / 10 \mu g$ & $1(6.7)$ & 14(93.3) \\
\hline Inhibitor & clavulanate & & & \\
\hline \multirow[t]{2}{*}{ Folate Inhibitor } & Trimethoprim- & $1.25 /$ & $0(0.0)$ & $15(100.0)$ \\
\hline & sulfamethoxazole & $23.75 \mu \mathrm{g}$ & & \\
\hline \multirow[t]{7}{*}{ Cephalosporins } & gen: & $30 \mu \mathrm{g}$ & $0(0.0)$ & $15(100.0)$ \\
\hline & Cefuroxime & & & \\
\hline & gen: & $30 \mu \mathrm{g}$ & $4(26.7)$ & $11(73.3)$ \\
\hline & Cefotaxime & & & \\
\hline & gen: & $30 \mu \mathrm{g}$ & $6(40.0)$ & $9(60.0)$ \\
\hline & Ceftazidime & & & \\
\hline & $4^{\text {th }}$ gen: Cefepime & $30 \mu \mathrm{g}$ & $7(46.7)$ & $8(53.3)$ \\
\hline Aminoglycosides & Gentamicin & $30 \mu g$ & $5(33.3)$ & $10(66.7)$ \\
\hline \multirow[t]{3}{*}{ Carbapenems } & Ertapenem & $10 \mu g$ & 8(53.3) & $7(46.7)$ \\
\hline & Meropenem & $10 \mu g$ & $9(60.0)$ & $6(40.0)$ \\
\hline & Imipenem & $10 \mu g$ & $11(73.3)$ & $4(26.7)$ \\
\hline Quinolones & Ciprofloxacin & $5 \mu g$ & $6(40.0)$ & $9(60.0)$ \\
\hline Tetracycline & Tetracycline & $30 \mu g$ & $0(0.0)$ & $15(100.0)$ \\
\hline
\end{tabular}

Key: $\mu \mathrm{g}=$ microgram, $\mathrm{n}=$ number, $\%=$ percentage, gen= generation

All $15(100 \%)$ of the Klebsiella pneumoniae isolates were at least multi-drug resistant, and out of the 15 isolates, 8 (53.3\%) were confirmed phenotypically as carbapenemase producers. The largest proportion of these phenotypic carbapenemase producers were seen in Klebsiella pneumoniae isolated from bed surfaces 4 (26.7\%). (Table 2) (Additional file 6: Figure S1).

Table 2: Distribution of carbapenemase production in the Klebsiella pneumoniae isolated from the sample sources 


\section{Sample Source (n) MDR Isolates, $\mathrm{n}(\%)$ Carbapenemase Production}

\begin{tabular}{llll}
\cline { 3 - 4 } & & Yes, $\mathrm{n}(\%)$ & No, $\mathrm{n}(\%)$ \\
\hline Beds (6) & $6(40.0)$ & $4(26.7)$ & $2(13.3)$ \\
Bed Tables (2) & $2(13.3)$ & $1(6.7)$ & $1(6.7)$ \\
Chlorhexidine (1) & $1(6.7)$ & $1(6.7)$ & $0(0.0)$ \\
Cupboards (4) & $4(26.7)$ & $2(13.3)$ & $2(13.3)$ \\
Hand Wash (1) & $1(6.7)$ & $0(0.0)$ & $1(6.7)$ \\
Forceps (1) & $1(6.7)$ & $0(0.0)$ & $1(6.7)$ \\
Total (15) & $\mathbf{1 5 ( 1 0 0 . 0 )}$ & $\mathbf{8 ( 5 3 . 3 )}$ & $\mathbf{7 ( 4 6 . 7 )}$ \\
\hline
\end{tabular}

Key: $\mathrm{n}=$ number, $\%=$ percentage, $\mathrm{MDR}=$ multi-drug resistant

The bla $\mathrm{KPC}_{\mathrm{C}}$ gene was undetected in the Klebsiella pneumoniae isolates (Figure 1).

\section{Discussion}

Klebsiella pneumoniae is a frequent cause of nosocomial infections, accounting for up to $10 \%$ of all nosocomial infections.[18] Carbapenems are the drugs of choice for the treatment of infections caused by drug resistant Enterobacteriaceae. [19] Unfortunately, rising bacterial resistance to carbapenems has been well documented.[20] Previous studies have shown that Klebsiella pneumoniae strains of environmental origin are similar to those of clinical origin in terms of biochemical patterns, virulence, and pathogenicity. However, clinical Klebsiella pneumoniae have been observed to be significantly more resistant to antibiotics when compared with environmental Klebsiella pneumoniae.[21]

Klebsiella pneumoniae was isolated from 15/534 (2.8\%) of the study population. A slightly lower rate was obtained in environmental isolates of Klebsiella pneumoniae in an Egyptian hospital, where 4/100 $(0.04 \%)$ of the study population was found to harbour Klebsiella pneumoniae.[22]

Out of 142 isolated organisms, 15 (10.6\%) were confirmed to be Klebsiella pneumoniae with 8(53\%) of these observed to be producing carbapenemases. A higher rate was observed in the northern region of Brazil, where 25/25 (100\%) of the Klebsiella pneumoniae isolates were confirmed as carbapenemase producers,[23] but much lower values were observed for clinical isolates of Klebsiella pneumoniae in a Chinese study 4/153 (2.6\%).[24] In Kano, Nigeria, a low prevalence of carbapenemase-producing Klebsiella pneumoniae was also observed 6/73 (8.2\%).[11] The varying prevalence of carbapenemase production could be a result of varying selection pressures from different antibiotic prescribing preferences in different countries. These varying observations were highlighted in a statement by Oduyebo et al., that carbapenemase production among the Enterobacteriaceae has been widely reported with prevalence ranges between $2.8 \%$ and $53.6 \%$.[10] 
The most frequent site of isolation was in beds $6 / 15$ (40\%), followed by bedside cupboards $4 / 15$ (26.7\%), and then bedside tables 2/15 (13.3\%). This finding was similar to that observed in Egypt, where the Klebsiella pneumoniae isolated from several ICUs were found more in beds, bedside tables, suction tubes, and ventilator tubes.[12] However no Klebsiella pneumoniae was isolated from the ICU in this study. This variation in the detection of the organisms from the ICUs of the different hospitals could be attributed to the maintenance of strict infection control measures in the ICU of NAUTH, Nnewi.

The antibiotic susceptibility patterns of the Klebsiella pneumoniae isolates revealed that the organisms had maximum resistance (100\%) to Ampicillin, Sulfamethoxazole-Trimethoprim, Cefuroxime, and Tetracycline, but were most susceptible to the Carbapenem class of antibiotics, in which Imipenem showed the most sensitivity (73.3\%). Contrasting findings were observed in an Egyptian study which revealed $100 \%$ resistance to Meropenem.[12] The reduced rates of resistance to the carbapenems in this study could be attributed to the limited use of carbapenems due to the high cost of purchase of these antibiotics in the country.

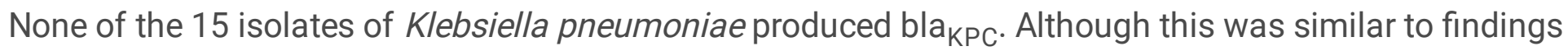
observed in previous Nigerian studies which dealt with clinical isolates of Klebsiella pneumoniae,[10][25] contrasting observations were seen in Maiduguri, Nigeria (6.5\%).[11] A significantly different finding was also observed in a Brazilian study that revealed that $100 \%$ of the Klebsiella pneumoniae isolates carried the bla $\mathrm{KPC}_{\mathrm{C}}$ gene.[23] The contrasting rates may be due to long term high use of carbapenems in Brazil, but the still recent introduction of these drugs in Nigeria.

The Klebsiella pneumoniae isolates were phenotypically positive for carbapenemase production on Modified Hodge Test but were negative for bla $_{\text {KPC }}$ gene on PCR. This could be because these isolates

harboured other carbapenemase-producing genes (including bla $\mathrm{NDM}_{\mathrm{N}} \mathrm{bla}_{\mathrm{VIM}}, \mathrm{bla}_{\mathrm{OXA}-48}$ etc), which were not searched for in this study.

\section{Conclusion}

Although the prevalence of carbapenemase production in the Klebsiella pneumoniae isolates was high, the rate of colonization of fomites with these pathogens in the NAUTH ward environment was still quite low, thus buttressing the need to reinforce strict infection control policies the hospital.

\section{Limitations}

All the genes responsible for carbapenemase production were not searched for. Although this limitation did not adversely affect the aim of this study, which was to determine carbapenemase production in the organisms, it would have been more accurate to detect all the genes responsible for its production. The phenotypic detection method (MHT) used in this study, helped to curb this limitation. Larger sample size may also have helped to improve the accuracy of the study. 


\section{Abbreviations}

MHT: Modified Hodges Test

NAUTH: Nnamdi Azikiwe University Teaching Hospital

KPC: Klebsiella pneumoniae Carbapenemase

MBL: Metallo- $\beta$-lactamase

VIM: Verona integron-encoded metallo- $\beta$-lactamase

NDM: New Delhi metallo- $\beta$-lactamase

OXA-48: Oxacillinases-48

ICU: Intensive Care Unit

MDR: Multi-drug resistant

ESBL: Extended Spectrum Beta-lactamase

PCR: Polymerase Chain Reaction

\section{Declarations}

\section{Ethics approval and consent to participate}

Ethical approval was obtained from the Research and Ethics Committee of Nnamdi Azikiwe University Teaching Hospital (NAUTH), Nnewi, with reference number NAUTH/CS/66/VOL.9/143/2016/11. Also, all isolates used in this study were obtained from inanimate materials in the wards of NAUTH, Nnewi, hence permission/consent to participate in the study was given by the Chairman Medical Advisory Committee on behalf of the NAUTH Board of Management, with reference number NAUTH/CS/152/VOL. 2/224.

\section{Consent for publication}

Not applicable.

\section{Availability of data and materials}

The necessary data generated or analysed during this study are included in this article (and its supplementary information files).

\section{Competing interests}


The authors declare that they have no competing interests.

\section{Funding}

This work and the subsequent article did not receive any form of financial support in the form of funding, grants or supplies.

\section{Author's contributions}

AIN and ACN designed the experiments and performed the literature search. All authors made conceptual contributions. AIN, AIM, ECJ, MNP, and UNG performed the laboratory experiments, as well as data acquisition. CCG and AIN analyzed the data. AIN wrote the manuscript. USN, UCF, and ACN edited and reviewed the manuscript. All authors read and approved the final version of the manuscript. AIN was the project leader, while ACN was the project supervisor.

\section{Acknowledgements}

Special appreciations go to Prof. Tatfeng Mirabeu (Coordinator, Molecular Biology Laboratory, Niger Delta University, Bayelsa, for his tutelage and assistance in the molecular analysis aspects of the work. We also acknowledge the technical assistance of Dr. Ikemefuna Onyeyili, as well as our research assistants; Cynthia, Favour, Mmesoma, and Matron Ezeji.

\section{Author information}

\section{Affiliations}

1. Department of Medical Microbiology/Parasitology, Faculty of Medicine, Nnamdi Azikiwe University, Awka.

2. Department of Community Medicine, Faculty of Medicine, Nnamdi Azikiwe University, Nnewi Campus.

3. Department of Nursing Sciences, School of Nursing, Nnamdi Azikiwe University Teaching Hospital, Nnewi.

4. Department of Medical Microbiology/Parasitology, Nnamdi Azikiwe University Teaching Hospital, Nnewi.

5. Department of Applied Microbiology and Brewing, Nnamdi Azikiwe University, Awka.

Aghanya $\mathrm{IN}^{1}$, Akujobi $\mathrm{CN}^{1}$, Ushie $\mathrm{SN}^{1}$, Ubajaka $\mathrm{CF}^{2}$, Ajuba $\mathrm{IM}^{1,3}$, Ezeama $\mathrm{CJ}^{1}$, Maduekwe NP${ }^{4}$, Uzoewulu $\mathrm{NG}^{1}$, Chigbo $\mathrm{CG}^{5}$.

\section{References}


1. Parisi SG, Bartolini A, Santacatterina E, Castellani E, Ghirardo R, Berto A et al. Prevalence of Klebsiella pneumoniae strains producing carbapenemases and increase of resistance to colistin in an Italian teaching hospital from January 2012 To December 2014. Bio Med Central Infectious Diseases. 2015;15:244.

2. Jones RN. Microbial Etiologies of Hospital-acquired Bacterial Pneumonia and Ventilator-associated Bacterial Pneumonia. Clinical Infectious Diseases. 2010;51(S1):S81-S87.

3. Peleg AY, Hopper DC. Hospital-Acquired Infections Due to Gram-negative Bacteria. New England Journal of Medicine. 2010;362:1804-1813.

4. Chen LF, Anderson DJ, Paterson DL. Overview of the epidemiology and the threat of Klebsiella pneumoniae carbapenemases (KPC) resistance. Infection and Drug Resistance. 2012;5:133-141.

5. Zhang X, Chen D, Xu G, Huang W, Wang X. Molecular epidemiology and drug resistant mechanism in carbapenem-resistant Klebsiella pneumoniae isolated from pediatric patients in Shanghai, China. PLOS ONE. 2018;13(3):e0194000.

6. Tadesse BT, Ashley EA, Ongarello $S$, et al. Antimicrobial resistance in Africa: a systematic review. BMC Infect Dis. 2017;17(1):616.

7. Belete MA, Saravanan M. A Systematic Review on Drug Resistant Urinary Tract Infection Among Pregnant Women in Developing Countries in Africa and Asia; 2005-2016. Infect Drug Resist. 2020;13:1465-1477

8. Nordmann P, Naas T, Poirel L. Global spread of Carbapenemase-producing Enterobacteriaceae. Emerging Infectious Diseases. 2011;17:1791-1798.

9. Ilaria F, Biasolo M, Bartolini A, Cavallaro A, Richter S, Palù G. Rapid detection of blaVIM-1-37 and blaKPC1/2-12 alleles from clinical samples by multiplex PCR-based assays. International Journal of Antimicrobial Agents. 2013;42(1):68-71.

10. Oduyebo OO, Falayi OM, Oshun P, Ettu AO. Phenotypic determination of carbapenemase producing enterobacteriaceae isolates from clinical specimens at a tertiary hospital in Lagos, Nigeria. Nigerian Postgraduate Medical Journal. 2015;22:223-227.

11. Mohammed Y, Zailani SB, Onipede AO. Characterization of KPC, NDM and VIM Type Carbapenem Resistance Enterobacteriaceae from North Eastern, Nigeria. Journal of Biosciences and Medicines. 2015;3:100-107.

12. Abdallah S, Zaki S, Hafez S, Moustafa E. Prevalence rate of Klebsiella pneumoniae in the intensive care unit: epidemiology and molecular characteristics. Journal of Biological Research - Bollettino Della Società Italiana Di Biologia Sperimentale, 2018;91(1).

13. Yusuf I, Magashi AM, Firdausi FS, Sharif AA, Getso MI, Bala JA, Aliyu IA. Phenotypic Detection of Carbapenemases in Members of Enterobacteriaceae in Kano, Nigeria. International Journal of Science and Technology. 2012;2(11):802-806.

14. Performance Standards for Antimicrobial Susceptibility Testing. Twenty- Seventh informational supplement. M100-S27. Clinical and Laboratory Standards Institute. Wayne, PA. 2017;37(1). 
15. De Medici D, Croci L, Delibato E, Di Pasquale S, Filetici E, Toti L. Evaluation of DNA extraction methods for use in combination with SYBR green I real-time PCR to detect Salmonella enterica serotype enteritidis in poultry. Environ. Microbiol. 2003;69:3456-3461.

16. Queipo-Ortuño MI, De Dios Colmenero J, Macias M, Bravo MJ, Morata P. Preparation of Bacterial DNA Template by Boiling and Effect of Immunoglobulin $G$ as an Inhibitor in Real-Time PCR for Serum Samples from Patients with Brucellosis. Clinical and Vaccine Immunology. 2008;15(2):293296.

17. Shanmugam P, Meenakshisundaram J, Jayaraman P. blaKPC gene Detection in Clinical Isolates of Carbapenem Resistant Enterobacteriaceae in a Tertiary Care Hospital. Journal of Clinical Diagnostics and Research. 2013;7(12):2736-2738.

18. Gorrie CL, Mirceta M, Wick RR, Edwards DJ, Thomson NR, Strugnell RA, Pratt NF, Garlick JS, Watson KM, Pilcher DV, McGloughlin SA, Spelman DW, Jenney AWJ, Holt KE. (2017). Gastrointestinal Carriage Is a Major Reservoir of Klebsiella pneumoniae Infection in Intensive Care Patients. Clin Infect Dis. 65(2):208-215.

19. Okoche D, Asiimwe BB, Katabazi FA, Kato L, Najjuka CF. (2015). Prevalence and Characterization of Carbapenem-Resistant Enterobacteriaceae Isolated from Mulago National Referral Hospital, Uganda. Zhang Q, ed. PLoS ONE. 10(8):e0135745.

20. Codjoe, F. S., \& Donkor, E. S. (2017). Carbapenem Resistance: A Review. Medical sciences (Basel, Switzerland). 6(1), 1.

21. Struve C, Krogfelt KA. (2004). Pathogenic potential of environmental Klebsiella pneumoniae Environmental microbiology. 6:584-590.

22. Mohamed ER, Aly SA, Halby HM, Ahmed SH, Zakaria AM, El-Asheer OM. (2017). Epidemiological typing of multidrug-resistant Klebsiella pneumoniae, which causes paediatric ventilator-associated pneumonia in Egypt. Journal of Medical Microbiology. 66:628-634.

23. Ferreira RL, Da Silva BC, Rezende GS, Nakamura-Silva R, Pitondo-Silva A, Campanini EB, Brito MCA, Da Silva EML, Freire C, Da Cunha AF, Pranchevicius MD. (2019). High Prevalence of MultidrugResistant Klebsiella pneumoniae Harboring Several Virulence and $\beta$-Lactamase Encoding Genes in a Brazilian Intensive Care Unit. Frontiers in Microbiology. 9(3389):1-15.

24. Du J, Li P, Liu H, Lü D, Liang H, Dou Y. (2014). Phenotypic and Molecular Characterization of Multidrug Resistant Klebsiella pneumoniae Isolated from a University Teaching Hospital, China. PLOS ONE. 9(4): e95181.

25. Onukwube CC, Agbakoba NR, Egwuatu CC, Aghanya IN. (2017). Detection of Carbapenem-Resistant Klebsiella pneumoniae Isolates from Clinical Specimens in Nnamdi Azikiwe University Teaching Hospital, Nnewi. International Journal of current Research and Review. 9(10):44-48.

\section{Figures}




\section{$\begin{array}{llllllllll}1 & 2 & 3 & 4 & 5 & 6 & 7 & 8 & \mathrm{C} & \mathrm{L}\end{array}$}

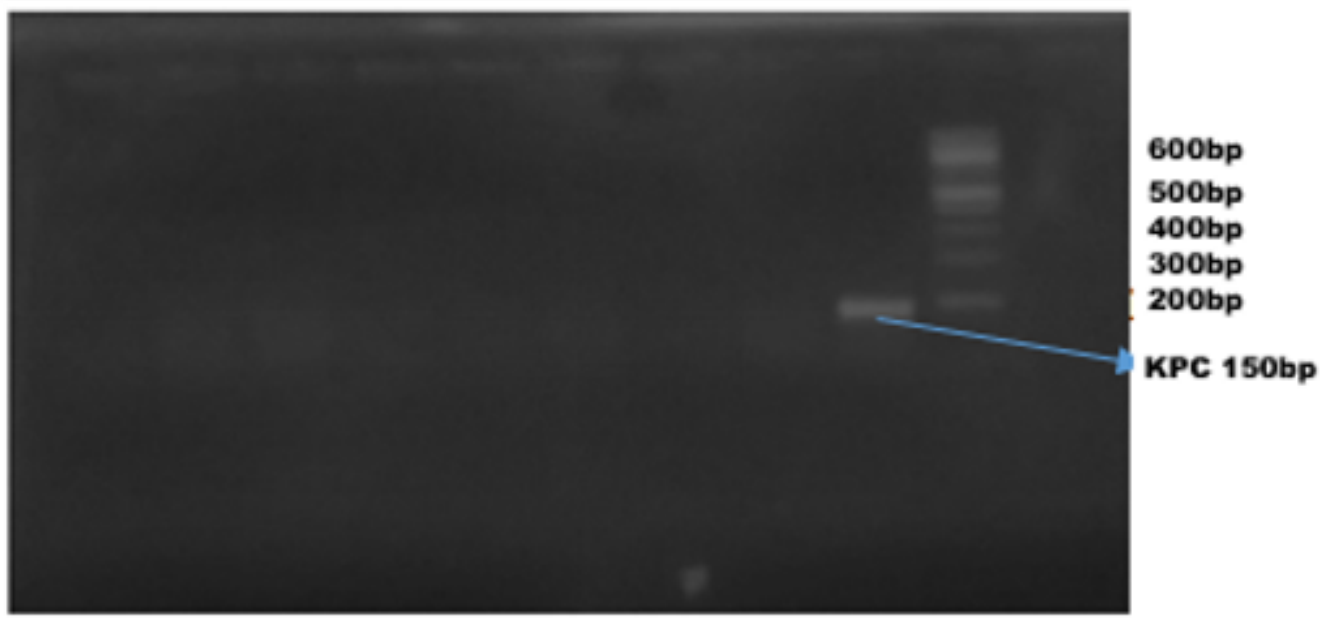

\section{Figure 1}

Agarose gel electrophoresis showing the amplified blaKPC gene from the bacterial isolates. Lanes 1-8 showed no amplification. Lane $C$ represents the blaKPC positive control. Lane $L$ represents the $100 \mathrm{bp}$ molecular ladder.

\section{Supplementary Files}

This is a list of supplementary files associated with this preprint. Click to download.

- TableS1.docx

- Tables2.docx

- TableS3.docx

- Tables4.docx

- TableS5.xIsx

- Figures1.docx 